\title{
Education for 'critical care without walls'
}

Philip Woodrow, MA, RGN, DipN, Grad Cert Ed, ENB 100, Practice Development Nurse, Intensive Therapy Unit, Kent \& Canterbury Hospital, East Kent Hospitals NHS Trust, Canterbury, Kent UK

e-mail: philip.woodrow@ekht.nhs.uk

Key words: acute care comprehensive critical care critically ill education high dependent patient

\begin{abstract}
This article describes how one National Health Service acute Trust in the UK developed an in-house course to support ward staff the care for acutely and critically ill patients.
\end{abstract}

\section{INTRODUCTION}

Handover has just finished. Your notes look like a hieroglyph of memos. IVIs, drugs going through syringe drivers and infusion pumps. Continuous oxygen, hourly urines, two hourly observations. And the real problems have not yet begun. Another shift, and once again you hope you can keep you neck above water. Sounds familiar? You are one of many nurses up and down the country struggling to provide the best care you can in a difficult situation. But the pressures never seem to ease.

Over the last decade greater numbers of increasingly sick patients have been cared for on most wards (Haines and Coad, 2001) due to:

\section{* increasing emphasis on productivity \\ * advances in drugs and other treatments enabling survival from illnesses that were previously fatal \\ * an ageing population \\ * limited critical care facilities, forcing acute wards to manage sicker patients.}

While the media and politicians battle over crises in healthcare, acute ward staff attempt to provide quality care. Government funding and initiatives attempt to relieve some of the worst pressures, but longer-term strategies are also needed.

The UK has the poorest provision of intensive care unit (ICU) beds in Europe (Daly et al., 2001), and so, not surprisingly, sicker patients (Miranda et al., 2001). Pressures on ICU inevitably mean increasingly sick patients being cared for on most wards. Vincent et al., (2001) found over 10\% of patients experienced adverse events, half of which were preventable. Costs, whether measured in quality of life, increased workload or money, are high. Yet poor outcomes and some deaths are potentially avoidable (McGloin et al., 1999).

Staff working on wards are best placed to recognise early complications and initiate appropriate interventions (Gibson, 1997).
However, preregistration courses have not adequately prepared staff to provide the level of care now needed by many patients, so staff need empowerment (Welch, 2000) through:

knowledge (education, professional development)
being allowed to initiate interventions (e.g. Patient
Group Directions).

\section{CRITICAL CARE WITHOUT WALLS}

Comprehensive Critical Care (Department of Health, 2000) should significantly alter acute healthcare services and workload of staff on acute wards, yet surprisingly few staff working in acute wards have even heard of this document. This fundamental review of critical care services in the UK recommended some radical changes.

Recognising that critically ill patients are being nursed in acute wards, and that this situation is unlikely to change, the report recommended replacing 'existing division into high dependency and intensive care based on beds ... by a classification that focuses on the level of care that individual patients need, regardless of location' (paragraph 16), or, in the report's own words, developing 'critical care without walls'. Wards caring for critically ill patients must have the resources to provide appropriate care.

Providing resources includes staff development. The report recommended providing 'modules on high dependency care for all ward staff working in acute hospitals' (paragraph 55), with targets that half of staff would undertake these modules by March 2002 and all by March 2004.

\section{Limitations of Comprehensive Critical Care}

Although bringing a welcome breath of idealism, making recommendations that should significantly improve healthcare for patients, and working conditions and job satisfaction for staff, expectations of what Comprehensive Critical Care can deliver should also be realistic. It will not reverse the causes of critically ill patients being cared for in acute wards. The NHS is currently experiencing many problems, including:

* chronic under-funding

* low staffing levels. 
low morale

excessive workload pressure.

Comprehensive Critical Care may help, but will not solve these problems. If, as the document suggests, critical care exists wherever there are critically ill patients, the recent BACCN position statement (Pilcher and Odell, 2000) defending nurse-patient ratios of 1:2 for highly dependent patients in critical care should imply that wards with critically ill patients need increased staffing establishments. However, recruitment and retention of nursing staff has long been problematic, and the UK spends less on health than most developed countries (Bion, 1995). Increased staffing is likely to remain an ideal rather than a reality for the near future.

\section{EAST KENT NHS TRUST}

East Kent NHS Trust was formed in 1999 when three former Trusts merged. This made it one of the UK's largest acute Trusts. With main hospitals in Ashford, Canterbury and Margate, and a number of smaller centres, it provides acute care for the people of East Kent.

Before Comprehensive Critical Care was published, the Trust, together with the Kent Education Consortium, had decided to fund a Trust-wide five-day course. Drawing on experience of courses already available both within East Kent NHS Trust and elsewhere, a five-day course was designed. Since my appointment in February 2001 to facilitate this course I have developed the module further in consultation with senior staff throughout the Trust.

\section{CARING FOR THE HIGHLY DEPENDENT PATIENT IN THE WARD ENVIRONMENT}

This course is divided into five themed days (see Tables 1 and 2), delivered on one day each week on each of the three main sites. Whenever possible, specialist speakers are invited to lead relevant sessions. The course aims:

* to provide knowledge and resources to support care of highly dependent patients

* to support evidence-based practice

* to encourage continuing professional development

* to challenge rituals of practice.

Places are limited to a maximum of twelve staff on each course. During the financial year 2001-2002 a total of twenty courses were provided.

The first day introduces the course, encourages staff to view care from the perspectives of acutely ill patients and their relatives, and emphasises the importance of assessment and prioritising, especially respiratory assessment and monitoring (McQuillan et al., 1997; Kenward et al., 2000; Chellel et al., 2002).

The second day explores a range of respiratory problems, treatments and aspect of care.

Day three focuses on cardiac problems and care.

Day four draws together how failure of other body systems can complicate critical illness, and care that can be provided to limit complications. To emphasise holistic nursing, the day concludes with focussing on people (patients and relatives) and their needs, rather than diseases.

The final day focuses on applying this course to practice.

There is time for a negotiated session; some of the more popular topics have been:
* pancreatitis

* chest drains

* diabetes and diabetic emergencies.

After evaluating the course, staff are invited to describe how they have been able to use the course in their clinical practice.

\section{Table 1. Course structure}

Day 1. Assessing \& Prioritising
Day 2. Respiratory
Day 3. Cardiovascular
Day 4. Homeostasis
Day 5. Theory into Practice

Table 2. Course timetable

All days run between 09.30-16.30

\begin{tabular}{|c|c|c|}
\hline$*$ & $\begin{array}{l}\text { Day } 1 \\
09.30 \\
13.15 \\
14.00\end{array}$ & $\begin{array}{l}\text { Assessing \& Prioritising } \\
\text { Introduction/ course expectations } \\
\text { Assessing the problem } \\
\text { Pulse oximetry } \\
\text { Lunch } \\
\text { Outreach service } \\
\text { Blood results } \\
\text { Pyrexia management } \\
\text { Groupwork }\end{array}$ \\
\hline$*$ & $\begin{array}{l}\text { Day } 2 \\
09.30 \\
11.00 \\
12.00 \\
14.00\end{array}$ & $\begin{array}{l}\text { Respiratory } \\
\text { Respiratory failure \& oxygen therapy } \\
\text { Physiotherapy } \\
\text { Suction } \\
\text { Tracheostomies } \\
\text { Non-invasive ventilation }\end{array}$ \\
\hline$*$ & $\begin{array}{l}\text { Day } 3 \\
09.30 \\
10.30 \\
14.00\end{array}$ & $\begin{array}{l}\text { Cardiovascular } \\
\text { Perfusion } \\
\text { Rhythm recognition } \\
\text { Care of patients with chest pain } \\
\text { Shock } \\
\text { Central venous pressure \& care of central lines }\end{array}$ \\
\hline$*$ & $\begin{array}{l}\text { Day } 4 \\
09.30 \\
11.30 \\
12.15 \\
14.00 \\
15.00\end{array}$ & $\begin{array}{l}\text { Homeostasis } \\
\text { Fluid balance \& acute renal failure } \\
\text { Fluid management } \\
\text { Care of patients with altered consciousness } \\
\text { Anaesthesia } \\
\text { Nutrition of the acutely ill } \\
\text { Acute management }\end{array}$ \\
\hline$*$ & $\begin{array}{l}\text { Day } 5 \\
09.30 \\
11.00 \\
12.00 \\
14.00 \\
15.00\end{array}$ & $\begin{array}{l}\text { Theory into Practice } \\
\text { Teamwork } \\
\text { Infection control } \\
\text { Negotiated session } \\
\text { Evaluation } \\
\text { Theory into practice: using this course }\end{array}$ \\
\hline
\end{tabular}

\section{EVIDENCE-BASED PRACTICE}

Although practice is expected to be evidence-based (Department of Health, 1999), nurses in clinical practice tend to rely on individuals whom they trust to provide reliable information rather than resorting themselves to texts and electronic sources (Thompson et al., 2001). This course therefore aims to provide evidence about clinical practice.

There is however a danger that evidence may be viewed as unquestionable, and so applied to practice uncritically (Ballinger and Wiles, 2001). Staff undertaking this course are therefore 
encouraged to reflect both on the course itself, and using it in clinical practice. To support this, the course handbook includes recommended further reading and resources, together with portfolio-style pages to reflect on study days, clinical practice and career development after the course. To encourage evidencebased practice, most sessions are supported with recent evidence and recommended further reading. Printouts of most sessions are provided for staff to copy.

Nursing has long been burdened with a theory-practice gap (Cook, 1991; Conway, 1994). To prevent this being a problem for this course, I spend one day each week giving direct patient care. I also offer support to individuals and staff in their own ward environment. Anecdotal comments from staff on recent courses suggests that staff from earlier intakes have successfully used this course to change and challenge practice. For example, use of fan therapy for pyrexial patients appears to have virtually vanished.

\section{EVALUATION}

Staff are asked to evaluate each session individually, and the course as a whole. Feedback so far has been strongly positive, and has helped the course develop to meet the needs of future staff. The most frequent concern is the pace at which the course is presented; many staff have suggested the course should be extended to more days. While extending the course is not practical at the moment, those interested are advised to pursue further specialist courses.

\section{CONCLUSION}

In Comprehensive Critical Care the Department of Health acknowledged that critically ill patients are being cared for on various ward areas, creating needs for staff development that were not being adequately met. The recommendation to provide modules on high dependency care for all acute hospital staff coincided with East Kent NHS Trust's plans to provide a five-day course. There are many problems facing staff working on acute wards, but courses such as this can improve patient care and provide a valuable incentive and resources to improve morale, recruitment and retention.

\section{REFERENCES}

Bion J. (1995). Rationing intensive care. British Medical Journal; 310: 682-683. Ballinger C, Wiles R. (2001). A critical look at evidence-based practice. British Journal Of Occupational Therapy; 64: 253-255.

Chellel A, Fraser J, Fender V, Higgs D, Buras-Rees S, Hook L, Mummery L, Cook C, Parsons S, Thomas C. (2002). Nursing observations on ward patients at risk of critical illness. Nursing Times; 98: 36-39.

Conway J. (1994). The art and science of nursing and the theory practice gap. British Journal Of Nursing; 3: 114-118.

Cook S. (1991). Mind the theory/practice gap in nursing. Journal Of Advanced Nursing: 16: 1462-1469.

Daly K, Beale R, Chang RWS. (2001). Reduction in mortality after inappropriate early discharge from intensive care unit: logistic regression triage model. British Medical Journal; 322: 1274-1276.

Department of Health. (1999). Making A Difference. London: Department of Health Department of Health. (2000). Comprehensive Critical Care. London: Department of Health.

Gibson JME. (1997). Focus of nursing in critical and acute care settings. Intensive \& Critical Care Nursing; 13: 163-166.

Haines S, Coad S. (2001). Supporting ward staff in acute care areas: expanding the service. Intensive \& Critical Care Nursing; 17: 105-109.

Kenward G, Hodgetts T, Castle N. (2001). Time to put the R back in TPR. Nursing Times; 97: 32-33.

McGloin H, Adam SK, Singer M. (1999). Unexpected deaths and referrals to intensivecare of patients on general wards. Are some cases potentially avoidable? Journal Of The Royal College Of Physicians Of London; 33: 255-259.

McQuillan P, Pilkington S, Allan A, Taylor B, Short A, Morgan G, Nielsen M, Barrett D, Smith G. (1998). Confidential inquiry into quality of care before admission to intensive care. British Medical lournal; 316: 1853-1858.

Miranda DR, Nap R. (2001). Intensive care in the UK - focus on some differences with other European countries. Care Of The Critically III; 17: 4-7.

Pilcher T, Odell M. (2000). Position statement on nurse-patient ratios in critical care. Nursing Standard; 15: 38-41.

Thompson C, McCaughan D, Cullum N, Sheldon TA, Mulhall A, Thompson DR. (2001). Research information in nurses' clinical decision-making: what is useful? Journal Of Advanced Nursing; 36: 376-388.

Vincent C, Neale G, Woloshynowych M. (2001). Adverse events in British hospitals: preliminary retrospective record review. British Medical Journal; 222:517-519.

Welch J. (2000). Using assessment to identify and prevent critical illness. Nursing Times; 96: 3-4. 